\title{
Hydration behavior and microstructural evolution of hydratable alumina with different particle size in alumina-spinel castables
}

\author{
Nana XU ${ }^{1,2}$, Yuanbing LI ${ }^{1,2, \dagger}$, Sheng FANG ${ }^{3}$, Shujing LI $^{1,2}$, Hailu WANG ${ }^{1}$, Ruofei XIANG ${ }^{1,2}$ and Si OUYANG ${ }^{1}$ \\ ${ }^{1}$ The State Key Laboratory of Refractories and Metallurgy, Department of Materials Science and Engineering, \\ Wuhan University of Science and Technology (WUST), Wuhan 430081, P. R. China \\ ${ }^{2}$ National-provincial Joint Engineering Research Center of High Temperature Materials and Lining Technology, \\ Wuhan University of Science and Technology (WUST), Wuhan 430081, P. R. China \\ ${ }^{3}$ Sinosteel Luoyang Institute Of Refractories Research Co., Ltd., Luoyang 471000, P. R. China
}

\begin{abstract}
Considering the same chemical compositions, the particle size of hydratable alumina (HA) is the key property related to the large differences in their rheology, sintering and thermal shock resistance. It is reasonable to consider that the benefits promoted by $\mathrm{HA}$, added as binder, would be affected by particle size changes. In this study, the design of alumina-spinel castables is optimized based on changing particle size to control HA hydration behavior. It is observed that the $\mathrm{pH}$ values and conductivities of $\mathrm{HA}$ slurry raise with decreasing particle size which indicates an increase in hydration rate of $\mathrm{HA}$. The finer $\left(\mathrm{d}_{50} 8.70 \mu \mathrm{m}\right) \mathrm{HA}$ are beneficial to motivate the hydration process and improve the mechanical properties of castables, and could also effectively enhance the thermal shock resistance as it can homogeneously hydrate in the matrix and significantly promote the sintering process. Accompanied with the dehydration and phase transformation of $\mathrm{HA}$, the high density of matrix structure can be found in the castables, which is responsible for an increase of mechanical performance. However, smaller particle size and higher specific surface area can also lead to severe hydration and excessive volume expansion of matrix cracks which could induce more microdamage during the hydration and dehydration.

(02019 The Ceramic Society of Japan. All rights reserved.
\end{abstract}

Key-words: Hydratable alumina, Particle size distribution, Conductivity, Microstructures, Thermal shock resistance

[Received October 9, 2018; Accepted February 4, 2019]

\section{Introduction}

Despite the substantial increase in world steel output (amounting to about one billion tons per year), the volume of production of refractories (whose major consumer is the metallurgy) has decrease markedly in recent years. ${ }^{1), 2)}$ The demand for refractories by the end of 2020 s is estimated to be about 18 billion euros. ${ }^{3)}$ The decrease in output of refractories are primarily due to the use of highquality raw materials and introduction of sophisticated high-technology equipment which increase their overall cost. ${ }^{4), 5)}$ Based on the data from the association of China refractories industry, the annual output of $u$ nshaped refractories in China is as high as 10 million tons, and its proportion in total refractories increases year by year. Hence, the key challenge in the development of unshaped refractories is the achievement of guaranteed mechanical properties and prolonged service time. ${ }^{6}$ )

Calcium aluminate cement (CAC) is the most widely used binders in refractory castable formulations to promote hardening mechanical strength. ${ }^{7), 8)}$ However, CACs gen-

Corresponding author: Y. Li; E-mail: lybref2002@126.com erate $\mathrm{CaO}$ which react with $\mathrm{Al}_{2} \mathrm{O}_{3}$ and $\mathrm{SiO}_{2}$ in the castable or slag to form low melting point substances such as yellow feldspar and anorthite during high-temperature calcination. ${ }^{9), 10)}$ In addition, hydrated minerals of CACs which dehydrate rapidly in the temperature of $800-1200^{\circ} \mathrm{C}$ that would cause lower strength and looser structure. ${ }^{11)}$ At present, multi-directional researches have been promoted on the purpose to make up defects of traditional CAC. Salman et al. ${ }^{12)}$ found that of properties of bauxite lowcement castables could be maintained by aforementioned phase formation occur at the lower temperatures from adding $\mathrm{Al}_{2} \mathrm{O}_{3}$ nanoparticles. Micro silica-based powder binders were proposed by Carmen et al, ${ }^{13)}$ which was valuable alternative to colloidal silica to achieve controllable curing time. Pandolfelli et al. ${ }^{14}$ ) began to use hydratable alumina (HA) to form similar hydration structure of CAC in castable. Hydratable alumina comprises a relative higher surface area (above $150 \mathrm{~m}^{2} / \mathrm{g}$ ) amorphous transition alumina phase which is known as $\rho$-alumina. ${ }^{15)}$ The $\rho$ alumina partially reacts with water, rapidly generating a pseudo-boehmite and boehmite gels. ${ }^{16)}$ This gel provides a larger volume and reduces the porosity of the structure, then crystallizes [bayerite, $\mathrm{Al}(\mathrm{OH})_{3}$ ] to bond the particles 
after a time usually shorter than $1 \mathrm{~h}$ (at temperatures above $\left.25^{\circ} \mathrm{C}\right) .{ }^{17), 18)}$

In the present work, a commercially available HA, is examined with respect to chemical analysis, particle size distribution (PSD), X-ray diffraction (XRD), then milled to different particle size and added into alumina-spinel castables. Hydration behavior of HA with different particle size are individually characterized with respect to XRD, integration calculate, true density and conductivity. Castables with different particle size of HA are characterized and compared in terms of mechanical properties and thermal shock resistance. The scanning electron microscopy (SEM) of fired samples are detected to characterize microstructures evolution of HA with different particle size in castables.

\section{Experimental procedure}

\subsection{Raw materials}

Commercial tabular alumina (Zhejiang Zili Co., Ltd., China), Spinel (Henan Special Refractories Co., Ltd., China), reactive $\alpha-\mathrm{Al}_{2} \mathrm{O}_{3}\left(\mathrm{~d}_{50} 2.2 \mathrm{~mm}\right.$, Alteo Gardanne, France) and HA (Zhengzhou Non-ferrous Metals Research Institute Co. Ltd. of CHALCO, China) are used as the raw materials. Chemical compositions of raw materials are presented in Table 1. In addition, Castament FS20 (BASF Consructuction Solutions $\mathrm{GmbH}$, Germany) is added as the water reducing agent of the castables. The batch compositions of the castables are shown in Table 2. HA particles are grinded by a planetary ball mill (XQM-10, Changsha Tianchuang Powder Technology Co., Ltd., China). After being milled with different milling time, HA shows different particle size distribution in Fig. 1. Due to the varied PSD from the change of milling time, the milled specimens are named HA-0, HA-3, HA-6, HA-9, and HA-12.

\subsection{Experimental procedure}

HA with different particle size would be subjected to mild stirring and dispersed by sonication ( $15 \mathrm{~min}$, run at $100 \mathrm{~W}$ and $42 \mathrm{kHz}$ ), as the mass ratio of distilled water and
HA is 2:1 and the stirring time is $60 \mathrm{~s}$. Then the slurry mixtures are subjected to $\mathrm{pH}$ and conductivity measurement and dried by the freeze-dryer. Finally, alumina-spinel castables bonded by HA with different particle size are prepared by casting as $40 \times 40 \times 160 \mathrm{~mm}$ and $25 \times 20 \times$ $140 \mathrm{~mm}$. Samples are dried at $110^{\circ} \mathrm{C}$ for $24 \mathrm{~h}$ and heated at $1550^{\circ} \mathrm{C}$ for $3 \mathrm{~h}$.

HA are subjected to XRD analysis using a powder diffractometer (X'pert ProMPD, PAnalyticalB.V., Netherlands) with a Ni-filtered $\mathrm{Cu} / \mathrm{K} \alpha$ radiation (Fig. 2). The PSD of HA are determined by using a laser diffraction particle size analyzer (Mastersizer2000, Malvern, UK) with detecting range of 0.04-2000 $\mu \mathrm{m}$. True densities are measured using automatic true density analyzer (ACCUPYC 1330, Micromeritics Instrument Corporation, Norcross, USA). Permanent linear change (PLC), apparent porosity (AP), bulk density (BD), cold modulus of rupture and crushing strength (CMOR/CCS) of the castables are measured according to ISO2477:2005, 5017:1998, 5014:1997 and 8895:2004, respectively. Wind quenching tests is referred to the Chinese standard YB/T 376.2-1995, and the specimens would be fired at $950 \pm 10^{\circ} \mathrm{C}$ for $30 \mathrm{~min}$, then being cooled by compressed air for $5 \mathrm{~min}$ to evaluate the

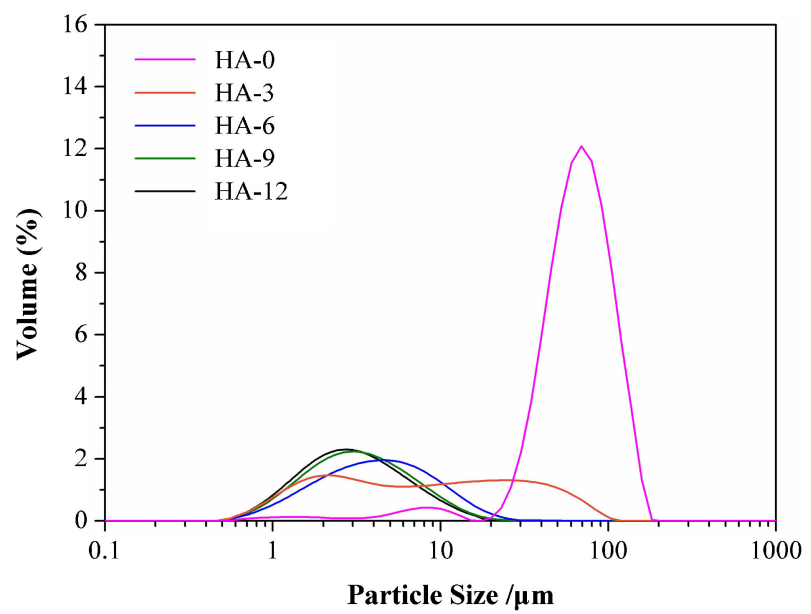

Fig. 1. Pore size distribution of HA vs. milling time.

Table 1. Chemical compositions of raw materials (wt \%)

\begin{tabular}{lcclcccccc}
\hline & $\mathrm{SiO}_{2}$ & $\mathrm{Al}_{2} \mathrm{O}_{3}$ & $\mathrm{Fe}_{2} \mathrm{O}_{3}$ & $\mathrm{CaO}$ & $\mathrm{MgO}$ & $\mathrm{K}_{2} \mathrm{O}$ & $\mathrm{Na}_{2} \mathrm{O}$ & $\mathrm{TiO}_{2}$ & $\mathrm{IL}$ \\
\hline Spinel & 0.26 & 72.87 & 0.39 & 0.38 & 25.56 & 0.01 & 0.18 & 0.01 & - \\
Tabular Alumina & 0.02 & 99.42 & 0.02 & - & - & - & 0.36 & - & - \\
$\alpha$-Alumina & 0.08 & 99.83 & 0.015 & 0.06 & - & - & 0.05 & - & - \\
Hydratable Alumina & - & 88.80 & 0.08 & 0.07 & 0.008 & 0.017 & 0.24 & - & 10.61 \\
\hline
\end{tabular}

Table 2. Basic formulations (wt \%)

\begin{tabular}{|c|c|c|c|c|c|}
\hline Materials & CHA-0 & CHA-3 & CHA-6 & CHA-9 & CHA-12 \\
\hline Tabular alumina Aggregates & & & 55 & & \\
\hline Tabular alumina powder $(\leq 74 \mu \mathrm{m})$ & & & 20 & & \\
\hline Reactive micro alumina (PBR) & & & 9 & & \\
\hline Spinel Aggregates & & & 8 & & \\
\hline Spinel powder $(\leq 74 \mu \mathrm{m})$ & & & 3 & & \\
\hline \multirow[t]{2}{*}{ Hydratable alumina (Different PSDs) } & & & 5 & & \\
\hline & HA-0 & HA-3 & HA-6 & HA-9 & HA-12 \\
\hline
\end{tabular}


thermal shock resistance of the castables. Pore size distributions are measured by mercury intrusion porosimetry measurement (Quantachrome PM60GT-18, Quantachrome Instruments Ltd., USA). Microstructures of castables are observed by SEM (Quanta 400, FEI Company, USA).

\section{Results and discussion}

\subsection{Calculation of hydrated alumina sintering}

After freeze-drying, the pseudo-boehmite and boehmite gels in slurry are dehydrated to form aluminium oxide hydated crystallite $[\gamma-\mathrm{AlO}(\mathrm{OH})$, boehmite $]$. The true densities of different HA hydrates before and after firing are illustrated in Table 3. Relative change of density before and after sintering $(\eta)$ are calculated by Eq. (1). The densification during sintering of the hydrated alumina is critically dependent on the density and size of a particle. As density and size of particles increases and decreases, respectively, relative change of density before

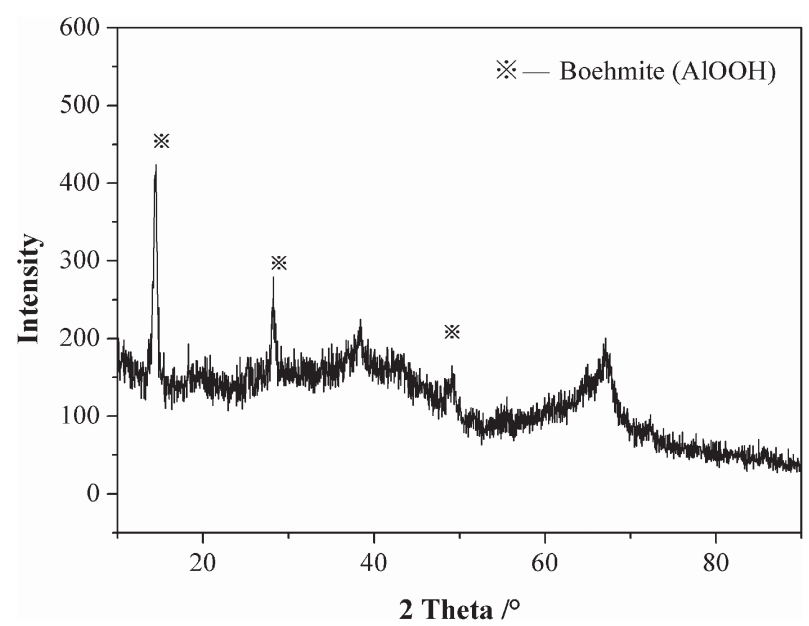

Fig. 2. X-ray diffractogram of HA. and after sintering $(\eta)$ increases: $40.0 \%$ for specimen HA- $0,42.9 \% \mathrm{~g} / \mathrm{cm}^{-3}$ for specimen HA-3, and $45.7 \%$ for specimen HA-12.

$$
\eta=100 * \frac{\rho_{\mathrm{s}}-\rho_{\mathrm{f}}}{\rho_{\mathrm{f}}}
$$

Where $\rho_{\mathrm{f}}$ and $\rho_{\mathrm{s}}$ are the true density of hydrated alumina before and after sintering, respectively. The results in Table 3 demonstrate that the densification rate of HA is proportional of PSD. Therefore, loose structure caused by severe hydration might be harmful for the grain growth during sintering. The results correspond to Three dimensional statistical-mechanical kinetic Monte Calro model which has been used by Bjørk ${ }^{19)}$ to prove that narrower PSD could contribute to the grain growth.

The structural and textural property changes during hydration and dehydration are summarized in Fig. 3. The hydrated crystallite would continue to dehydrate from the molecular interlayer during the sintering process. Since the lower particle size are easier to form thicker hydration layer, and lead to the decrease of the hydration density (Table 4). Hence, the relationship between particle size and grains growth must be investigated from the viewpoint of the sintering behavior of materials, in order to balance these characteristics for the fabrication of denser products with high strength.

Table 3. Relative change of density before and after sintering from hydrated alumina with different PSDs

\begin{tabular}{lccc}
\hline & $\begin{array}{c}\rho_{\mathrm{f}} \\
\left(\mathrm{g} / \mathrm{cm}^{-3}\right)\end{array}$ & $\begin{array}{c}\rho_{\mathrm{s}} \\
\left(\mathrm{g} / \mathrm{cm}^{-3}\right)\end{array}$ & $\begin{array}{c}\eta \\
(\%)\end{array}$ \\
\hline HA-0 & 2.780 & 3.892 & 40.0 \\
HA-3 & 2.747 & 3.925 & 42.9 \\
HA-6 & 2.745 & 3.933 & 43.3 \\
HA-9 & 2.726 & 3.937 & 44.4 \\
HA-12 & 2.712 & 3.951 & 45.7 \\
\hline
\end{tabular}

(a)

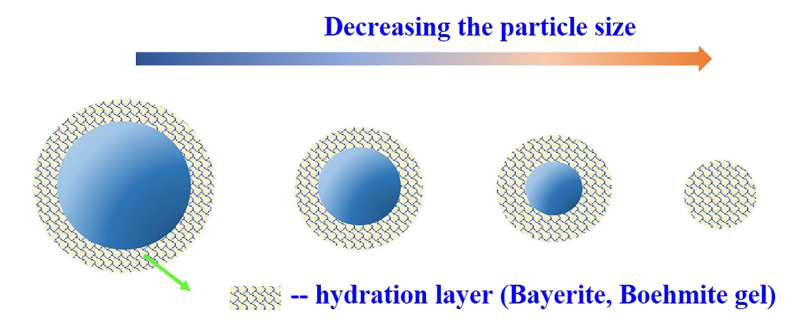

(b)
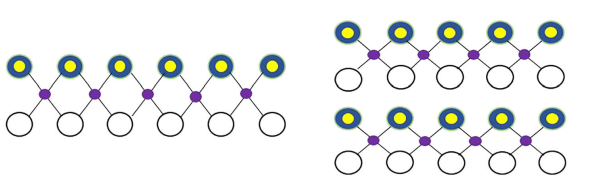

○ --OH $\quad$--Al

--O
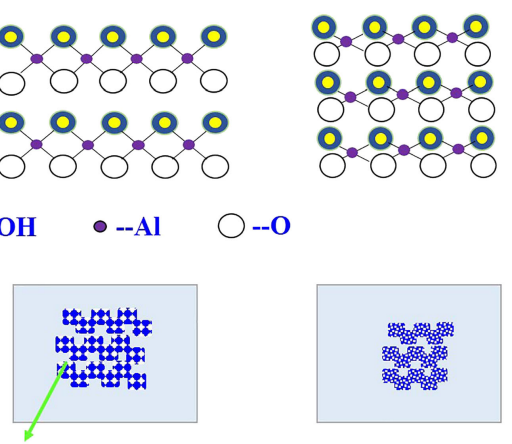

Hydrated alumina

(c)

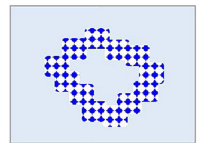

Remains hydrated structure
Boehmite alumina

Freeze-dryer

Transition alumina

Dehydration

Fig. 3. Schematic illustration of the mechanism of the structural and textural property changes during hydration process. 

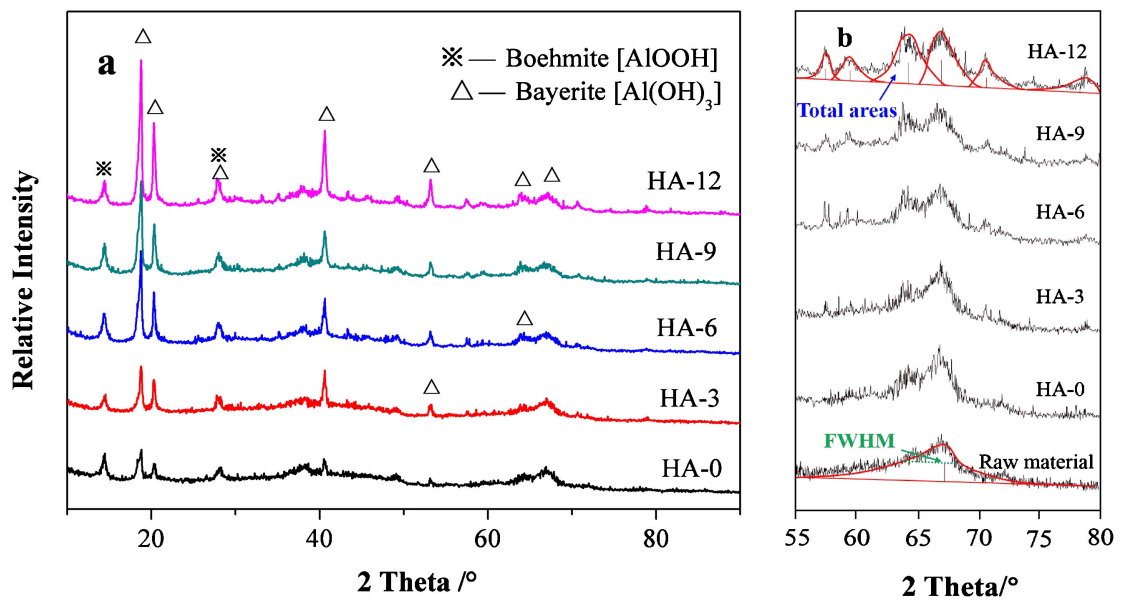

Fig. 4. X-ray diffractograms of hydrated alumina with different PSD.

Table 4. The effects of PSD on the hydration properties after freeze-drying

\begin{tabular}{lccccc}
\hline & HA-0 & HA-3 & HA-6 & HA-9 & HA-12 \\
\hline Conductivities $(\mathrm{mS} / \mathrm{cm})$ & 0.404 & 0.495 & 0.521 & 0.862 & 1.320 \\
pH values & 8.76 & 10.32 & 10.36 & 11.07 & 11.40 \\
Total areas & 1783.13 & 1874.25 & 20610.83 & 2529.70 & 2665.52 \\
\hline
\end{tabular}

\subsection{Hydration and crystallization process of $\mathrm{HA}$}

Hydration behavior are detected by using a separate environment operating at stable setting conditions would contribute to character the effects of particle size on the hydration behavior. Figure 3 shows the XRD patterns of hydrated HA of different PSD. It reveals that the major phases are boehmite $(\mathrm{AlOOH})$ and bayerite $\left[\mathrm{Al}(\mathrm{OH})_{3}\right]$. Observed from Fig. 4(a), the diffraction peaks in the region of $18-22^{\circ}$ become more and more obvious and the increased peak intensity shows more clearly defined bayerite structure in the hydrates. As bayerite is of the highest symmetry among $\mathrm{Al}(\mathrm{OH})_{3}$ structures and is the thermodynamically most stable phase, it is always initial formed crystalline. ${ }^{20), 21)}$ This could also be verified by the integration areas of peaks shown in Table 4 which is calculated by the integration of Profit Software. In the region of $55-80^{\circ}$ [Fig. 4(b)], the diffraction peak gradually changes from an amorphous state to sharp peaks with the decrease of particle size. This may be formed by lyophilization and dehydration of pseudo-boehmite and boehmite gels when phase from amorphous structure moves to crystalline indicating a increase in molecular order. ${ }^{22)}$ Meanwhile, the decrease of particle size could effectively promote the hydration of HA, and free hydroxyl $(\mathrm{OH})$ from the increasing boehmite gel significantly enhance the $\mathrm{pH}$ values and conductivities of the slurry (Table 4).

\subsection{Physical properties of HA bonded castables}

Figures 5-7 show the physical properties of castables after curing at room temperature and drying at $110^{\circ} \mathrm{C}$ for $24 \mathrm{~h}$. It can be observed from Fig. 5 that CHA-3 samples

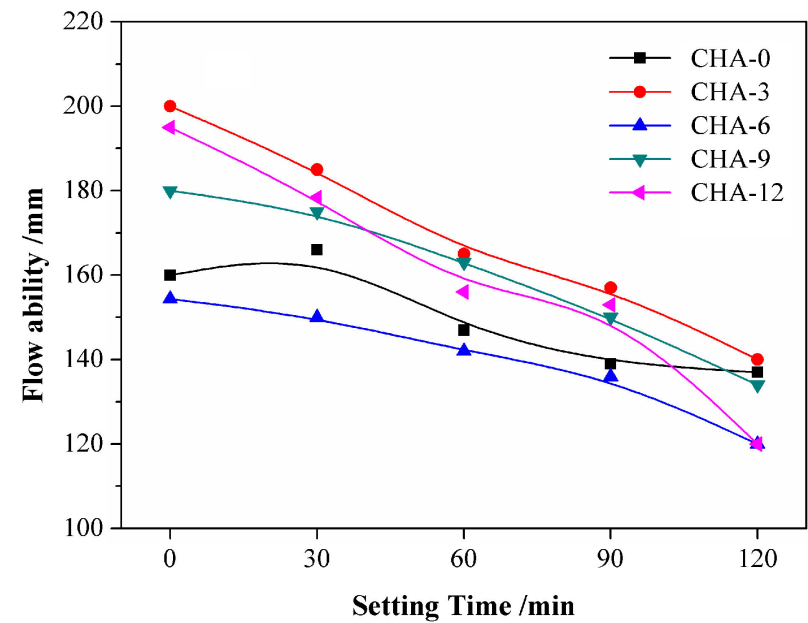

Fig. 5. Effects of PSD on the flow ability of castables $\left(110^{\circ} \mathrm{C} \times 24 \mathrm{~h}\right)$.

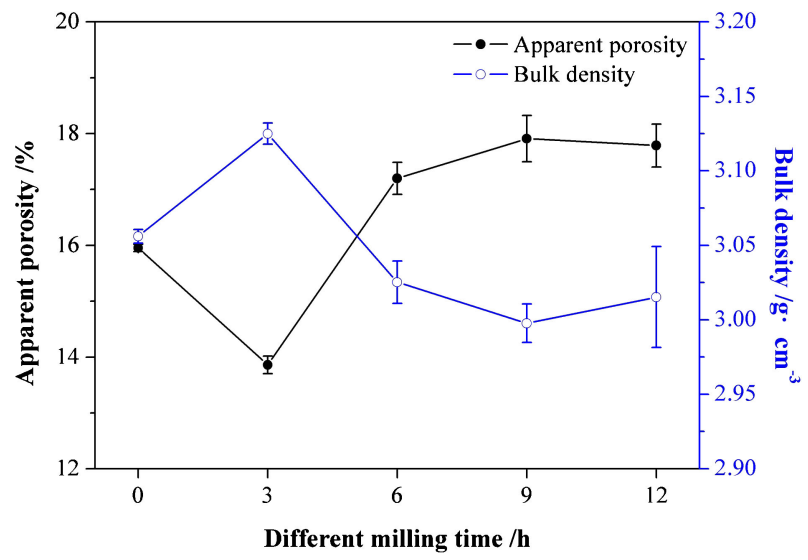

Fig. 6. Effects of PSD on the $\mathrm{AP}$ and $\mathrm{BD}$ of castables $\left(110^{\circ} \mathrm{C} \times 24 \mathrm{~h}\right)$.

have better flow abilities and lower decay rate as the setting time going, indicating better work ability. As shown in Figs. 6 and 7, the BD of the samples increase first and then drop with the particle size decrease of HA, and the apparent porosities (AP) show opposite changes. The reduc- 


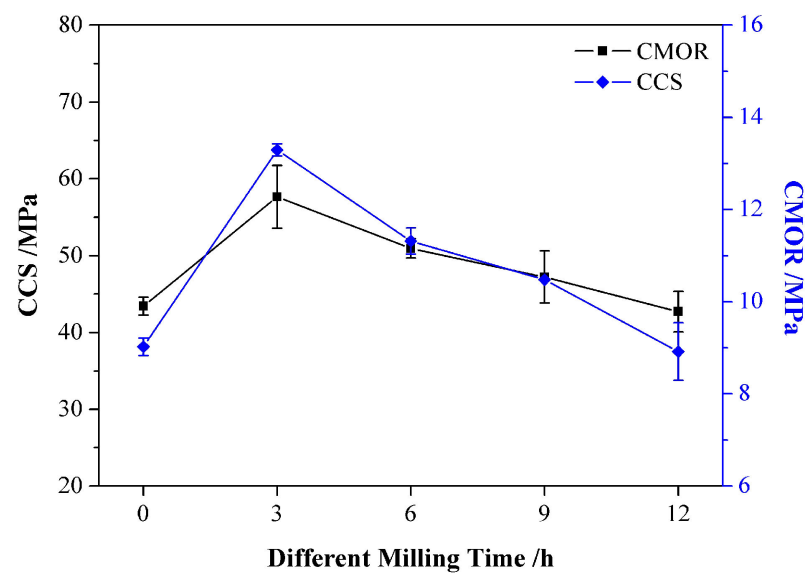

Fig. 7. Effects of PSD on the CMOR/CCS of castables $\left(110^{\circ} \mathrm{C} \times 24 \mathrm{~h}\right)$.

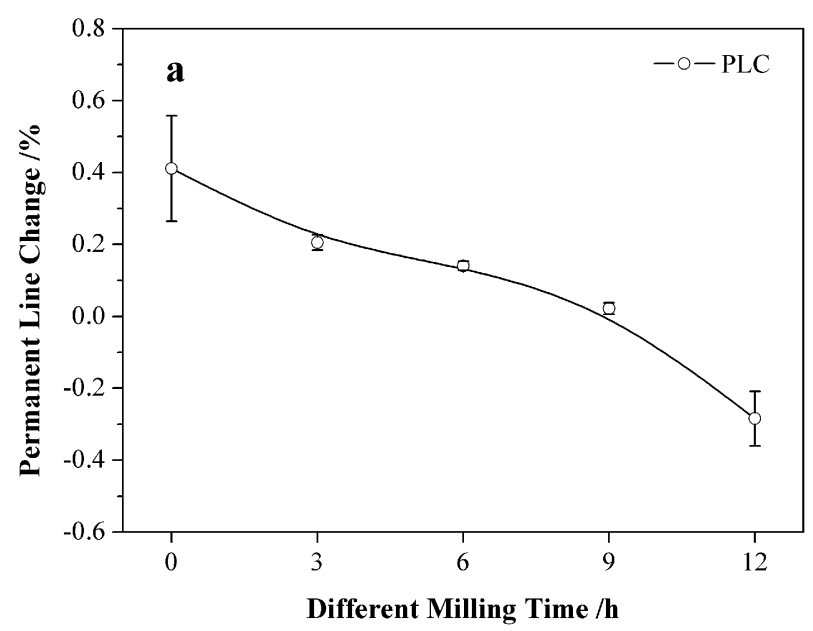

Fig. 8. Effects of PSD on the PLC of castables $\left(1550^{\circ} \mathrm{C} \times 3 \mathrm{~h}\right)$.

tion of particle size could raise the specific surface area of $\mathrm{HA}$, and promote the probability of participating in the hydration reaction, to form pseudo-boehmite and boehmite gels in castable system. For the sample CHA-3, uniform bimodal PSD of HA contribute to denser matrix structure. At the meantime, the products of hydration reaction help that some interparticle pores are transformed into intraparticle pores, and many close pores are formed, those may lead to decrease in AP. Along with the continuously transform of PSD from broad to narrow, the more and more rapid hydration heat would make the matrix structure loose and increase particles agglomeration which could have negative influence on the strength of samples. ${ }^{23), 24)}$

Figures 8-10 illustrates the physical properties of castables after firing at $1550^{\circ} \mathrm{C}$ for $3 \mathrm{~h}$. As shown in Fig. 8, the PLC continuously decreases with the particle size dropping while volume expansion of castables gradually turns to be volume shrinkage. Mechanical properties show better performance for sample CHA-3 in Figs. 9 and 10. The pore size distributions of castables (Fig. 11) are mainly bimodal distributed in two narrower ranges of $0.1-6$ and $6-20 \mu \mathrm{m}$. In the range of $0.1-6 \mu \mathrm{m}$, pore size distribution of different castables trend to be narrower with

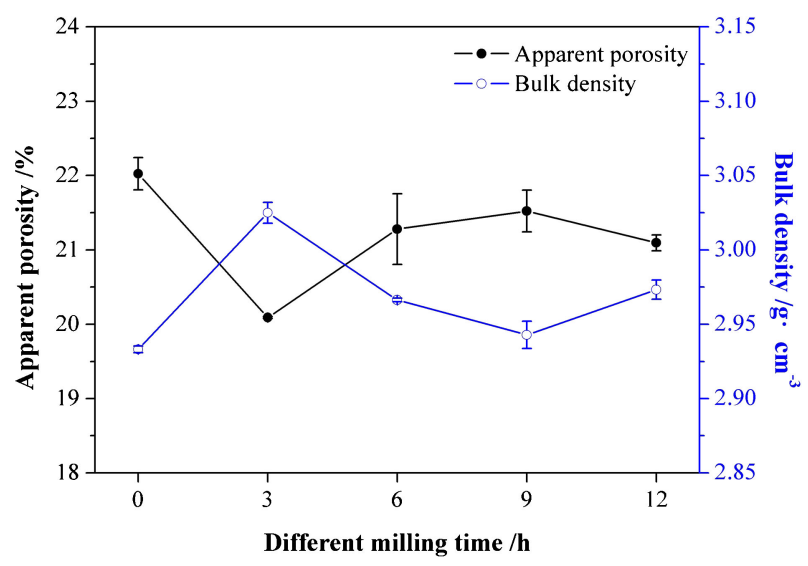

Fig. 9. Effects of PSD on the $\mathrm{AP}$ and $\mathrm{BD}$ of castables $\left(1550^{\circ} \mathrm{C} \times 3 \mathrm{~h}\right)$.

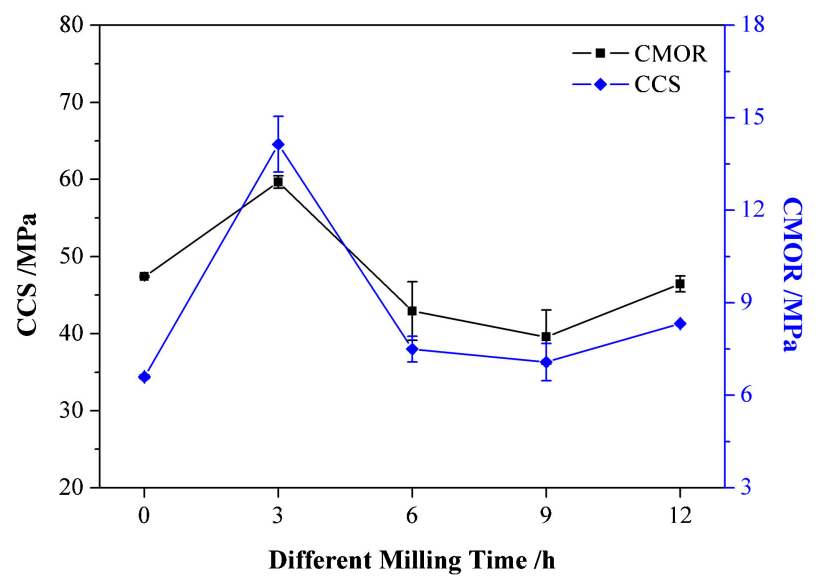

Fig. 10. Effects of PSD on the CMOR/CCS of castables $\left(1550^{\circ} \mathrm{C} \times 3 \mathrm{~h}\right)$.

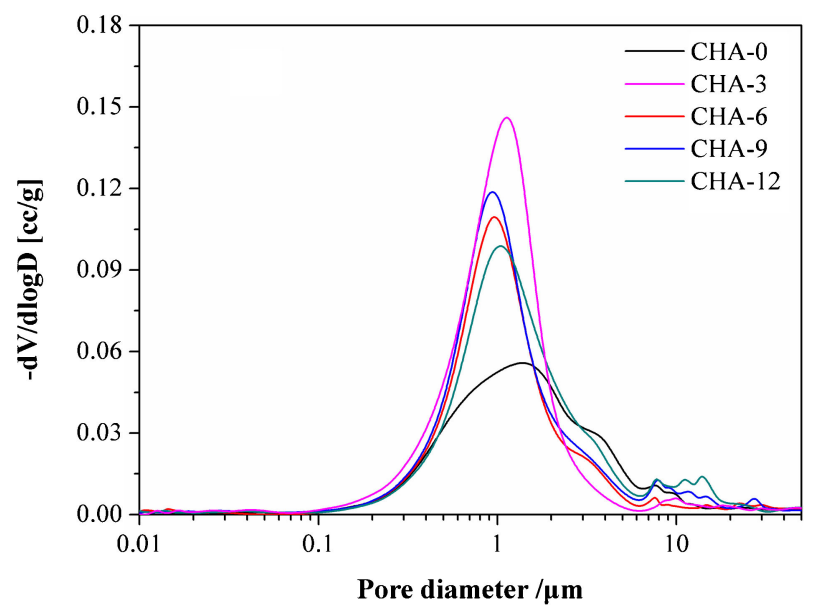

Fig. 11. Effects of PSD on the pore size distribution of castables $\left(1550^{\circ} \mathrm{C} \times 3 \mathrm{~h}\right)$.

the particle size decreasing, especially for the sample CHA-3, most of which are distributed below $2 \mu \mathrm{m}$. Meanwhile, relative larger pores in the range of $6-20 \mu \mathrm{m}$, show a different change compared with smaller region. CHA-3 samples almost could not detected to form relative larger pores in this region, and the CHA- 0 and CHA- 12 samples 

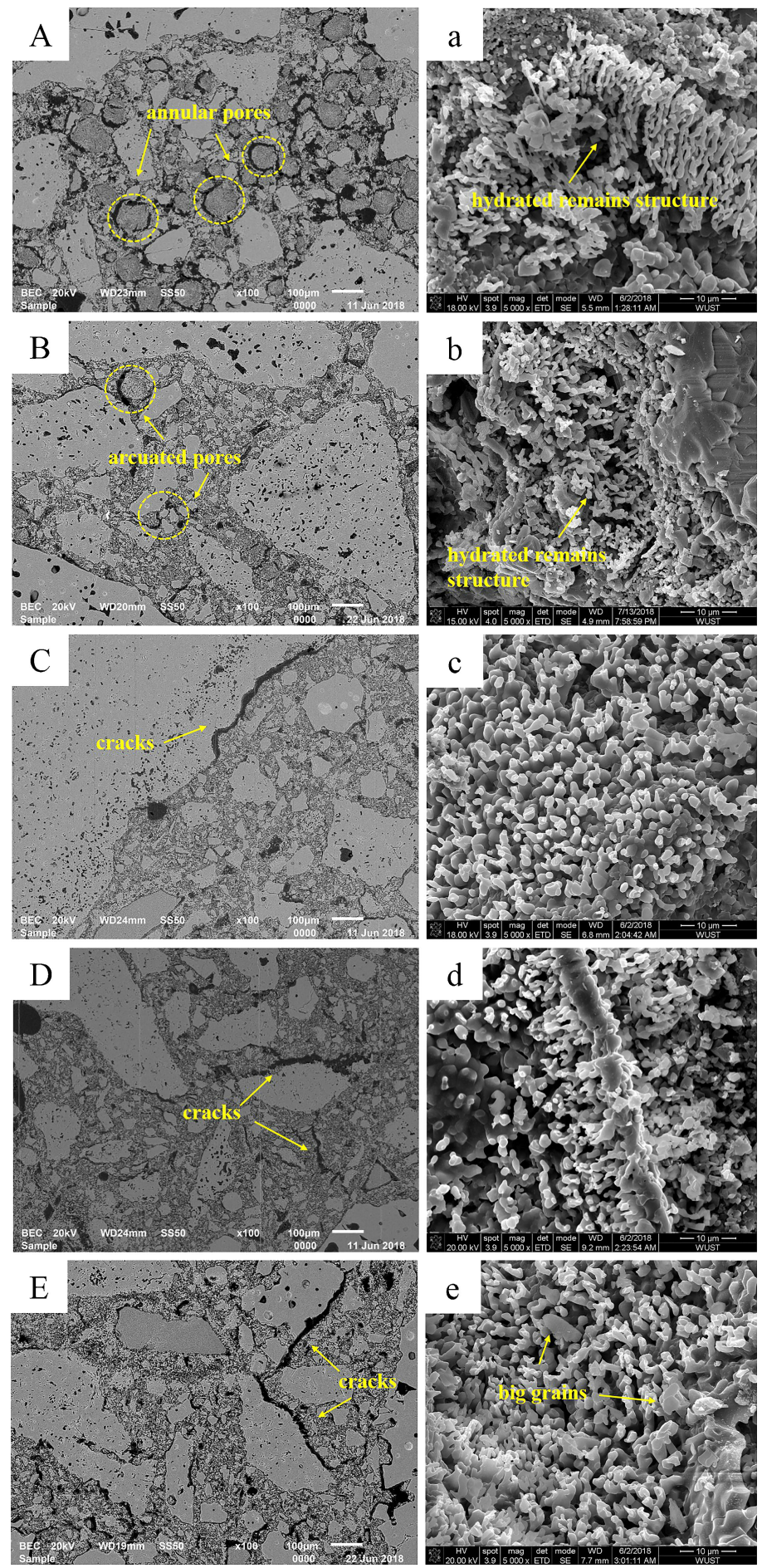

Fig. 12. SEM micrographs of alumina-spinel castables fired at $1550^{\circ} \mathrm{C}$. For samples: (A) CHA-0, (B) CHA-3, (C) CHA-6, (D) CHA-9 and (E) CHA-12.

hold more areas of larger pores than others. More larger pores in matrix would do harm to physical properties, leading to the decrease of CCS and CMOR in Fig. 11. This may result from that the relative thicker hydration layer in the samples is difficult to bonded by sintering, then to form pores around the hydrated alumina. But, on the other hand, smaller particle size could contribute to the sintering reaction, leading to a slight increase of mechanical strength in sample CHA-12. Some interparticle pores are transformed into intraparticle pores that would lead to decrease in closed porosity and increase in the growth of grains, which will be further discussed in the below.

In order to assess microstructural changes in aluminaspinel castables that containing different PSD of HA, microstructure images (SEM) of the apparent morphology and fracture surfaces of castables after drying and sintering at $1550^{\circ} \mathrm{C}$ are shown in Fig. 12. For sample CHA-0 with coarse HA particles, annular pores are generated in the 


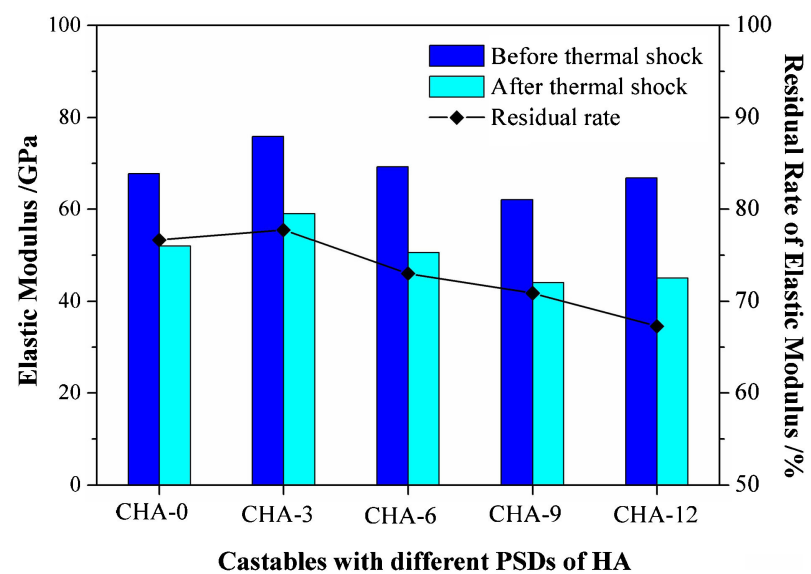

Fig. 13. Change in residual elastic modulus of fired castables after thermal shock $\left(950^{\circ} \mathrm{C}\right.$ recycle 5 times).

matrix [Fig. 12(a)]. With the changing of PSD with HA, the uniform bimodal PSD of HA contribute to form denser matrix structure and symmetric hydration products in sample CHA-3. Furthermore, the hydrated alumina begins to agglomerate in samples CHA-6, CHA-9 and CHA-12 which have apparent cracks propagated along the boundaries of tabular alumina and the looser matrix structure, as shown in Figs. 12(D)-12(F). Crystal structure evolution of HA is also shown in the Fig. 12. The worm-like alumina which has the special layered distribution locates on the surround of hexagonal alumina [Fig. 12(a)]. The typical feature of hydration structure interpreted in Fig. 4 has been reserved in the matrix structure after sintering, which lead to the loose of density and decrease of strength. Based on the previous research, ${ }^{25), 26)}$ grain growth begins earlier in the sintering cycle at lower densities for broad PSD, reducing the number and area of grain necks available for densification by annihilation. With the HA changing from HA-0 to HA-12, the grain sizes of HA show a trend to increase after sintering. Compared with other samples, narrower PSD of CHA-12 show a relative rapidly growth of grain size [Fig. 12(e)]. Combined with the calculation results in Table 4 and mechanical properties in Fig. 10, the evolution of HA microstructures suggest that PSD can be used effectively to control the microstructure of the final sintered component and promote the strength. If variations in microstructure with low relative density are desired, the exact microstructure can be tailored with a choice of PSD.

Figure 13 presents the residual elastic modulus for the samples with varied PSD of HA. After 5 times of thermal shock, all the samples showed the same trend to decrease. It is worthy to be mentioned that the residual elastic modulus of samples CHA-9 and CHA-12 show the faster speed to drop down. Carolan et al. ${ }^{27)}$ theoretically certificated that increasing the grain size might make the thermal shocked ceramic have a higher residual strength and a better resistance to crack expanding. However, the extent of crack propagation increases with the raise of cracks numbers and volumes, which is mainly associated to the agglomeration of hydrated alumina in the matrix.

\section{Conclusions}

The effects of HA particle size on the hydration behavior of HA and physical properties of alumina-spinel castables are investigated in this study. The results can be summarized as follows:

Hydration process of HA could be promoted by the change of PSD. The crystallinity and particle size of bayerite and boehmite increase rapidly due to the decrease of particle size. As the results, the XRD patterns and relative sintered densities of varied hydrates show quiet differences. Conductivities and $\mathrm{pH}$ values are shown to act as adequate indicators of active hydroxyl in boehmite gel, indirectly reflecting the hydrates concentration.

This work has also highlighted the importance of PSD of HA when assessing the effect that its variation has on castables performance. Different PSD of binders could contribute to build various characters of matrix structures, and lead to differences in strength and thermal shock resistance. Moreover, mechanical activation increases the specific surface area by decreasing particle size and resulting in an increase of the active surface. These activated particles can participate in the sintering reactions, then the reaction kinetics may significantly change in terms of their acceleration, which leads to significant improvements in the grains size.

Acknowledgments The authors appreciate the financial support from National Natural Science Foundation of China (No. $51772221 \& 51502213$ ).

\section{References}

1) A. Salomon, M. Dopita, M. Emmel and S. Dudczig, J. Eur. Ceram. Soc., 35, 795-802 (2015).

2) J. L. Guo, Y. P. Bao and M. Wang, Waste Manage., 78, 318-330 (2018).

3) I. M. S. K. Ilankoon, Y. Tang, Y. Ghorbani and S. Northey, Miner. Eng., 125, 206-222 (2018).

4) S. Mula, P. Padhi, S. Panigrahi and S. K. Pabi, Mater. Res. Bull., 44, 1154-1160 (2009).

5) S. Mukhopadhyay, Mater. Res. Bull., 48, 2583-2588 (2013).

6) Y. Pachaury and P. Tandon, J. Manuf. Process., 25, 369-390 (2017).

7) D. H. Wang, C. J. Shi, N. Farzadnia, Z. G. Shi, H. F. Jia and Z. H. Ou, Constr. Build. Mater, 181, 659-672 (2018).

8) R. Salomão, V. L. Ferreira, I. R. D. Oliveira, A. D. V. Souza and W. R. Correr, J. Eur. Ceram. Soc., 36, 42254235 (2016).

9) E. Z. Hayati, O. M. Moradi and M. G. Kakroudi, Mater. Design, 45, 571-575 (2013).

10) A. K. Singh and R. Sarkar, J. Alloy. Compd., 758, 140147 (2018).

11) J. Czechowski and I. Majchrowicz, Ceram. Int., 44, 10335-10339 (2018).

12) S. Ghasemi-Kahrizsangi, H. G. Dehsheikh, E. Karamian and M. Boroujerdnia, Ceram. Int., 43, 8813-8818 (2017).

13) O. Burgos-Montes, M. Álvarez, A. H. de Aza and P. 
Peña, J. Eur. Ceram. Soc., 38, 4137-4148 (2018).

14) R. Salomao and V. C. Pandolfelli, Ceram. Int., 35, 3117-3124 (2009).

15) W. Ma and P. W. Brown, J. Am. Ceram. Soc., 82, 453$456(2010)$.

16) B. E. Yoldas, J. Chem. Technol. Biot., 23, 803-809 (2010).

17) R. Salomão and V. C. Pandolfelli, Am. Ceram. Soc. Bull., 86, 9301-9306 (2007).

18) A. Kaneyasu, S. Yamamoto and A. Yoshida, Taikabutsu Overseas, 17, 21-26 (1996).

19) R. Bjørk, V. Tikare, H. L. Frandsen and N. Pryds, J. Am Ceram. Soc., 96, 103-110 (2013).

20) X. Du, X. Su, Y. Wang and J. G. Li, Mater. Res. Bull., 44, 660-665 (2009)
21) K. Dolling, A. Brasch, United State Patent, No. 6773690 (2012).

22) Y. K. Park, E. H. Tadd, M. Zubris and R. Tannenbaum, Mater. Res. Bull., 40, 1506-1512 (2005).

23) Y. S. Liu, B. Q. Han, T. Zhang and H. Yu, Ceram. Int., 42, 16961-16968 (2016).

24) T. S. Yeh and M. D. Sacks, J. Am. Ceram. Soc., 71, 484-487 (1988).

25) F. S. Shiau, T. T. Fang and T. H. Leu, J. Am. Ceram. Soc., 80, 286-290 (1997).

26) S. K. Nath, S. Kuma and R. Kumar, Bull. Mater. Sci., 37, 1221-1226 (2014).

27) D. Carolan, A. Ivankovic and N. Murphy, J. Eur. Ceram. Soc., 32, 2581-2586 (2012). 